\title{
Structural Abnormalities on MRI in Cases with Epilepsy
}

\author{
Gaurav Kaushik ${ }^{\circledR}$, Madan Manmohan ${ }^{\circledR}$ \\ Department of Radiodiagnosis, DY Patil University School of Medical, Sector 7, Nerul, Navi Mumbai, Maharashtra, India.
}

\section{Abstract}

Introduction: Many treatable anatomical abnormalities of the brain can cause seizures. The present study was done to determine the role of MRI for evaluation of patients with epilepsy. Subjects and Methods: Patients who presented to our hospital with history of epilepsy. i.e two or more episodes of unproved seizures 24 hours apart, underwent MRI study to assess for abnormalities. Patients of either gender and all age groups who were referred to our department for MRI study were included. Results: Generalized tonic clonic seizures were present in $86 \%$ of the population and rest had partial seizures. Using MRI, we arrived at a diagnosis as a cause of seizure in $51.3 \%$ of the patients and rest of the $48.7 \%$ had a normal MRI study. The most common pathology detected on MRI was infarct with gliosis (24.7\%). Less common pathology detected were neurocysticercosis $(6.7 \%)$, brain atrophy (5.3\%), tuberculoma (3.3\%), venous thrombosis $(2.7 \%)$, developmental malformations (2.7\%), glioma (1.3\%), cavernoma (1.3\%), tuberous sclerosis $(1.3 \%)$, meningioma $(0.7 \%)$, cerebral abscess $(0.7 \%)$ and Sturge Weber syndrome $(0.7 \%)$. Abnormality on MRI was not significantly associated with gender or type of seizure. MR abnormality was observed maximum in patients between 1 to 30 years (30 out of 70 patients i.e. $42.8 \%$ ) while all the elderly cases showed abnormal MRI, with infract with gliosis being the most common finding. Conclusions : MR imaging should be the first investigation of choice in epileptic syndrome, cerebrovascular disease with seizure, developmental cortical malformations, and vascular malformations.

Keywords: Epilepsy, Etiology, Magnetic Resonance Imaging, Seizure

Corresponding Author: Gaurav Kaushik, Department of Radiodiagnosis, DY Patil University School of Medical, Sector 7, Nerul, Navi Mumbai, Maharashtra, India.

E-mail: gauravkaushik_7@yahoo.co.in

Received: 08 June 2020

Revised: 09 July 2020

Accepted: 18 July 2020

Published: 30 December 2020

\section{Introduction}

Seizure is an excessive hyper synchronous electrical discharge from a set of neurons in the central nervous system. Each burst of electrical activity is called seizure. Epilepsy has been defined as "two or more unprovoked seizures occur at an interval more than 24 hours apart". ${ }^{[1]}$ Various epidemiology studies in India have reported widely varying prevalence rates ranging between 1.3 and 11.9 per 1,000 population. ${ }^{[2]}$ Considering a conservative estimate of $1 \%$ as prevalence of epilepsy, there are more than 12 million persons with epilepsy in India, which contributes to nearly one-sixth of the global burden. Epilepsy can occur due to a metabolic disturbance, physiological imbalance or a structural abnormality. With the advent of modern surgical techniques, many of the structural abnormalities can be treated. As a result neuroimaging which can diagnose surgically amenable lesions in epileptic patients has become an important aspect of diagnosing epilepsy. ${ }^{[3]}$ The International League Against Epilepsy recommends computerized tomography (CT) scanning of head in all patients with epilepsy regardless of the cause and type of the seizures. Moreover, CT-negative cases should be further explored with magnetic resonance imaging (MRI). ${ }^{[4,5]}$ At present, MRI is the imaging modality of choice in epileptic cases due to its ability to depict neuroanatomy, excellent grey white matter differentiation, status of myelination and detection of focal structural brain lesions which can act as the foci of seizures. MRI is also a useful tool in the determination of prognosis and for follow up. The present study was done to determine the role of MRI for evaluation of patients with epilepsy.

\section{Subjects and Methods}

\section{Study Design and Sampling}

The present observational study was conducted on patients who were referred to the Department of Radiodiagnosis at a tertiary care teaching hospital in Navi Mumbai. During January 2014 till June 2015, consecutive patients who presented to the emergency or medicine outpatient clinic with history of epilepsy i.e two or more episodes of unproved 
seizures 24 hours apart. Patients of either gender and all age groups who were referred to our department for MRI study were included. We excluded those patients in whom MRI was contraindicated. The purpose of the study was explained to the patients. Written informed consent was obtained from adults aged more than 18 years and assent was obtained from cases less than 18 years of age, co-signed by their parents.

\section{Magnetic Resonance Imaging technique}

MRI was performed in all cases on single slice helical "GE Optima 1.5T" machine. Standard head coil \& NV coil was used for imaging in MRI. Management was given in all patients as per standard hospital protocol. Proper position of the patient was done (head first, supine). Sedation was given as and when required (very young patients with chances of motion during the study, claustrophobic patients). Sedation was either oral (syrup Pedichloryl- half hour before the study) or intra-venous (Ketamine/ Propofol- before start of study was administered by the attending anesthetist). Conventional MR imaging consisted of $\mathrm{T} 1$ and $\mathrm{T} 2$ weighted and FLAIR sequences in axial plane. Diffusion weighted and gradient echo axial images were also obtained. Flair, IR \& T1 3D TFE sequence obtained in oblique coronal plane to study hippocampal sclerosis. If required, T1-weighted fat saturated spin-echo sequence after intravenous injection of $0.1 \mathrm{mmol} / \mathrm{kg}$ gadopentetatedimeglumine was obtained in axial, sagittal and coronal sequences. The slice thickness was 3 to $5 \mathrm{~mm}$. The overall duration of the examination was 20 minutes. Diffusion and diffusion weighted imaging was performed in axial plane. Diffusion was obtained at 0,500 and 1000 values. The data collected was then transferred to the post processing software for interpretation and ratios.

\section{Data Collection and Data Analysis}

Using a pre-designed semi-structured questionnaire, the demographic details of the patients were noted. The medical history of the patients was obtained from the medical records. Statistical analysis was done in SPSS (version 23, IBM). The data were presented descriptively as proportions. Association of various variables was analysed using chi-square test, considering $p$ value of less than 0.05 as statistically significant.

\section{Results}

In the present study, we included 150 cases fulfilling our study criteria. [Table 1] describes the baseline characteristics of the patients. In our study population, 1 to 15 years was the most common age group (26\%), followed by 16 to 30 years (24\%) and less than 1 year $(20.7 \%)$. Male comprised of $63.3 \%$ of the study population. Generalized tonic clonic seizures were present in $86 \%$ of the population and rest had partial seizures. Of those with partial seizers $(n=21)$, most common were myoclonic partial seizures $(n=8)$, simple partial seizures $(n=3)$, absence seizures $(n=2)$, temporal lobe seizures $(n=2)$, complex partial seizures $(n=2)$ and one case each of tonic seizures, motor seizures, neonatal seizures and febrile seizures. Using MRI, we arrived at a diagnosis as a cause of seizure in $51.3 \%$ of the patients and rest of the $48.7 \%$ had a normal MRI study. The most common pathology detected on MRI was infarct with gliosis $(24.7 \%)$. Of these patients, 8 had acute infarct in parieto-occipital lobes, 2 had subacute hematoma in parietal lobe, 3 had abnormality like narrowing of cortical arterial branches, 9 had chronic ischemic changes with gliosis in left fronto-parietal lobe, 2 had cystic encephalomalacia changes in right parieto- occipital lobe, 2 had tiny chronic ischemic lesions in deep white matter and one patient had an old infarct with gliosis in parietal lobe and deep gray matter nuclei. Less common pathology detected were neurocysticercosis $(6.7 \%)$, brain atrophy $(5.3 \%)$, tuberculoma $(3.3 \%)$, venous thrombosis (2.7\%), developmental malformations (2.7\%), glioma (1.3\%), cavernoma $(1.3 \%)$, tuberous sclerosis $(1.3 \%)$, meningioma $(0.7 \%)$, cerebral abscess $(0.7 \%)$ and Sturge Weber syndrome $(0.7 \%)$. Furthermore, it was observed that males had higher proportion of cases who had abnormalities on MRI (54\%) as compared to those of female cases (45\%), although the difference was not statistically significant [Table 2] (p value $=0.27$ ). In addition, cases with partial seizures had more proportion of abnormalities on MRI (62\%) as compared to general tonic clonic seizures $(49 \%)$, however the difference was not significant ( $p$ value $=0.29$ ). [Table 3] describes that MR abnormality was observed maximum in patients between 1 to 30 years ( 30 out of 70 patients i.e. $42.8 \%$ ) while all the elderly cases showed abnormal MRI, with infract with gliosis being the most common finding.

\section{Discussion}

Neuroimaging in the early course of epilepsy is important as it can identify etiology and guide therapeutic approaches. MRI imaging can not only identify nonspecific abnormalities of the central nervous system like periventricular leucomalacia and atrophy, it can demonstrate static remote lesions as well. It can also isolate focal lesions responsible for seizures like cortical dysplasias and mesial temporal sclerosis, which can be treated with epilepsy surgery. Additionally, it can diagnose subacute and chronic processes like metabolic disorders and it is important for identifying acute process requiring emergent intervention like tumor, stroke, encephalitis and hydrocephalus. ${ }^{[5]}$ The present study was conducted to assess MRI findings in cases diagnosed with seizures. We were able to locate MRI abnormalities in $51.3 \%$ of the patients. Singh et al reported a detection rate for structural abnormalities of $64 \% .{ }^{[6]}$ While few studies have reported even higher detection rates $(>80 \%)$, some investigators reported a poor detection rate. ${ }^{[7]}$ There have been studies in past wherein superiority of MRI has been demonstrated over CT in intractable epilepsy. 
Table 1: Baseline characteristics of the patients included in the study

\begin{tabular}{|c|c|c|}
\hline Variables & $\mathbf{N}$ & $\%$ \\
\hline \multicolumn{3}{|l|}{ Age groups (in years) } \\
\hline$<1$ & 31 & $20.70 \%$ \\
\hline 1 to 15 & 39 & $26.00 \%$ \\
\hline 16 to 30 & 37 & $24.70 \%$ \\
\hline 31 to 45 & 18 & $12.00 \%$ \\
\hline 46 to 60 & 14 & $9.30 \%$ \\
\hline$>60$ & 11 & $7.30 \%$ \\
\hline \multicolumn{3}{|l|}{ Gender } \\
\hline Female & 55 & $36.70 \%$ \\
\hline Male & 95 & $63.30 \%$ \\
\hline \multicolumn{3}{|l|}{ Type of epilepsy } \\
\hline Partial & 21 & $14 \%$ \\
\hline General tonic clonic & 129 & $86 \%$ \\
\hline \multicolumn{3}{|c|}{ Cause of seizure based on MRI findings } \\
\hline Normal Study & 73 & $48.70 \%$ \\
\hline Infract with gliosis & 37 & $24.70 \%$ \\
\hline Neurocysticercosis & 10 & $6.70 \%$ \\
\hline Atrophy & 8 & $5.30 \%$ \\
\hline Tuberculoma & 5 & $3.30 \%$ \\
\hline Venous Thrombosis & 4 & $2.70 \%$ \\
\hline $\begin{array}{l}\text { Developmental Mal- } \\
\text { formations }\end{array}$ & 4 & $2.70 \%$ \\
\hline Glioma & 2 & $1.30 \%$ \\
\hline Cavernoma & 2 & $1.30 \%$ \\
\hline Tuberous Sclerosis & 2 & $1.30 \%$ \\
\hline Meningioma & 1 & $0.70 \%$ \\
\hline Cerebral Abscess & 1 & $0.70 \%$ \\
\hline $\begin{array}{l}\text { Sturge Weber Syn- } \\
\text { droms }\end{array}$ & 1 & $0.70 \%$ \\
\hline
\end{tabular}

Some of these initial studies were done using a low resolution scanner, which resulted in a lower detection rates for structural lesions. ${ }^{[8]}$

It was observed that most common age group in our study was up to 30 years. Similar observations were made by Sheikh et al who found 25 to 34 years age group to be at an increased risk of seizures. ${ }^{[9]}$ Another study from India reported similar results. ${ }^{[10]}$ Studies from developed countries report a bimodal distribution in the incidence of seizures. This variation may be explained by the variations in the demographic composition of the populations. In younger age groups, we found infarct with gliosis and neurocysticercosis to be more common, while infarct with gliosis was more common in cases aged more
Table 2: Association of abnormal findings on MRI with patient related variables

\begin{tabular}{llll}
\hline $\begin{array}{l}\text { Patient } \\
\text { variables }\end{array}$ & \multicolumn{2}{l}{ MRI findings } \\
& $\begin{array}{l}\text { Normal } \\
(\mathbf{n}=73)\end{array}$ & Abnormal $(\mathbf{n}=\mathbf{7 7})$ \\
\hline $\begin{array}{l}\text { Gender } \\
\text { Female }\end{array}$ & $30(55 \%)$ & $25(45 \%)$ & 0.27 \\
\hline $\begin{array}{l}\text { Male } \\
\text { Type } \\
\text { seizure }\end{array}$ & $43(46 \%)$ & $52(54 \%)$ & \\
\hline $\begin{array}{l}\text { Partial } \\
\text { General } \\
\text { tonic clonic }\end{array}$ & $8(38 \%)$ & $13(62 \%)$ & 0.29 \\
\hline
\end{tabular}

Table 3: Cause of seizures with respect to age group of the patients

\begin{tabular}{|c|c|c|c|c|c|c|c|}
\hline \multirow[b]{2}{*}{$\begin{array}{l}\text { Cause } \\
\text { of } \\
\text { Seizure }\end{array}$} & \multicolumn{7}{|c|}{ Age group (in years) } \\
\hline & $\begin{array}{l}< \\
1\end{array}$ & $\begin{array}{l}1 \\
\text { to } \\
15\end{array}$ & $\begin{array}{l}16 \\
\text { to } \\
30\end{array}$ & $\begin{array}{l}31 \\
\text { to } \\
45\end{array}$ & $\begin{array}{l}46 \\
\text { to } \\
60\end{array}$ & $\begin{array}{l}> \\
60\end{array}$ & Total \\
\hline $\begin{array}{l}\text { Infract } \\
\text { with } \\
\text { gliosis }\end{array}$ & 6 & 8 & 5 & 4 & 6 & 8 & 37 \\
\hline Neurocy & 0 & 2 & 5 & 2 & 1 & 0 & 10 \\
\hline Atrophy & 5 & 1 & 1 & 0 & 0 & 1 & 8 \\
\hline Tubercul & 0 & 1 & 4 & 0 & 0 & 0 & 5 \\
\hline $\begin{array}{l}\text { Venous } \\
\text { Throm- } \\
\text { bosis }\end{array}$ & 3 & 0 & 0 & 4 & 0 & 0 & 4 \\
\hline $\begin{array}{l}\text { Develop: } \\
\text { Mal- } \\
\text { forma- } \\
\text { tions }\end{array}$ & 0 & 1 & 0 & 0 & 0 & 0 & 4 \\
\hline Glioma & 0 & 1 & 0 & 0 & 0 & 1 & 2 \\
\hline Caverno: & 0 & 0 & 1 & 0 & 0 & 1 & 2 \\
\hline $\begin{array}{l}\text { Tuberou } \\
\text { Scle- } \\
\text { rosis }\end{array}$ & 0 & 1 & 1 & 0 & 0 & 0 & 2 \\
\hline Meningi & 0 & 0 & 0 & 1 & 0 & 0 & 1 \\
\hline $\begin{array}{l}\text { Cerebral } \\
\text { Abscess }\end{array}$ & 0 & 0 & 1 & 0 & 0 & 0 & 1 \\
\hline $\begin{array}{l}\text { Sturge } \\
\text { Weber } \\
\text { Syn- } \\
\text { droms }\end{array}$ & 0 & 1 & 0 & 0 & 0 & 0 & 1 \\
\hline
\end{tabular}


than 60 years of age. Gaillard at al reported that among children with partial seizures, outcome can be predicted with initial MRI results. ${ }^{[11]}$ Similarly in cases with temporal lobe epilepsies, abnormalities detected on MRI were found to be an independent predictor of seizure outcome. ${ }^{[12]}$ So published reported suggest that neuroimaging is important for choosing therapeutic approaches in childhood cases and thus estimate the prognosis of the disease to adulthood period. In addition, cases in our study were predominantly males. Sheikh et al reported a similarly higher incidence among males. Poor reporting due to cultural factors, lower utilization of healthcare services and differentially higher mortality among female children due to poor care might have contributed to this difference. ${ }^{[13]}$

We observed that $48 \%$ of the cases of seizures had no structural abnormality on MRI. Among those with MR abnormality, infarct with gliosis was the most common finding. GTCS were more common than partial seizures. This is similar to what has been reported in previous studies from India. ${ }^{[14]}$ However, this finding is in contrary to other studies in past which shows partial seizure to be most common presentation. ${ }^{[15]}$ This might be explained owing to lack of reliable witnesses to the seizure events or poor recall of events.

We observed that abnormality on MRI was not significantly associated with gender of the patient or type of seizure. Among elderly patients, infarct with gliosis was the most common finding. Similar to our observations, many studies have reported that the most common cause of seizures in the elderly is cerebrovascular disease. ${ }^{[16]}$ Hemorrhagic strokes are more likely to be associated with seizures than infarcts and $20 \%$ to $50 \%$ of epilepsy in the elderly is related to cerebrovascular disease. ${ }^{[17]}$ Some investigators have highlighted the bidirectional relationship of stroke and seizures as the risk of stroke is increased in patients with late-onset seizures. ${ }^{[18]}$ It is therefore advisable to investigate patients with late-onset seizures for stroke risk factors and treat them appropriately.

Functional MRI, SPECT and PET also help to localize the seizure focus and completment the MRI study. ${ }^{[19]}$ However, their availability and cost restricts their routine usage, though they can be used in patients with abnormal MRI or abnormal electroencephalography. ${ }^{[20]}$ Colosimo $\mathrm{C}$ et al confirmed the superiority of MRI over CT with respect to the histology of the tissue and the assessing the spread of the tumor. ${ }^{[21]}$ Though CT can be used in emergency cases (acute intracranial hypertension) to identify hydrocephalus and intratumoral hemorrhages, MRI can present a more comprehensive picture with minimal radiation exposure.

\section{Conclusion}

MR imaging should be the first investigation of choice in epileptic syndrome, cerebrovascular disease with seizure, developmental cortical malformations, and vascular malformations. It can detect structural abnormalities which can be treated surgically. It can pick subtle cortical abnormalities, hippocampal lesions as well as characterize lesions like different types of tumours and infections with its advanced applications.

\section{References}

1. Krauss G. Epilepsy Is Not Resolved. Epilepsy Curr. 2014;14(6):339-340. Available from: https://dx.doi.org/10. 5698/1535-7597-14.6.339.

2. Panagariya A, Sharma B, Dubey P, Satija V, Rathore M. Prevalence, Demographic Profile, and Psychological Aspects of Epilepsy in North-Western India: A Community-Based Observational Study. Annals of Neurosciences. 2018;25(4):177-186. Available from: https://dx.doi.org/10.1159/000487072.

3. Kuzniecky RI. Neuroimaging of epilepsy: Therapeutic implications. NeuroRX. 2005;2(2):384-393. Available from: https://dx.doi.org/10.1602/neurorx.2.2.384.

4. Fisher RS. ILAE official report: a practical clinical definition of epilepsy. Epilepsia. 2014;55:475-482. Available from: https://doi.org/10.1111/epi.12550.

5. Gaillard WD, Chiron C, Cross JH, Harvey AS, Kuzniecky R, Hertz-Pannier L, et al. Guidelines for imaging infants and children with recent-onset epilepsy. Epilepsia. 2009;50(9):21472153. Available from: https://dx.doi.org/10.1111/j.1528-1167. 2009.02075.x.

6. Jain RS, Khan I, Nagpal K. Identification of structural lesion using a 3-Tesla MRI in partial onset epilepsy with a normal CT scan: A perspective of a tertiary centre in Northern India. Indian J Med Spec. 2018;9(4):187-191. Available from: https: //dx.doi.org/10.1016/j.injms.2018.05.008.

7. Craven IJ, Griffiths PD, Bhattacharyya D, Grunewald RA, Hodgson T, Connolly DJ, et al. Hoggard N. 3.0 T MRI of 2000 consecutive patients with localisation-related epilepsy. $\mathrm{Br}$ J Radiol. 1017;85:1236-1278. Available from: https://dx.doi. org/10.1259/bjr/30177037.

8. Rysz A, Bidziński J, Gołebiewski M, Kroh H, Bonicki W. The value of structural neuroimaging in the selection of patients for epileptic surgery. Neurol Neurochir Pol. 1998;32(2):217-242.

9. Sheikh NA, Shabnum N, Bhat GA, Kawoosa A, Mushtaq M, Wani MA. Etiological profile of adult onset seizures: a hospital based prospective study from Kashmir, India. Int J Adv Med. 2017;4(3):793-793. Available from: https://dx.doi.org/ 10.18203/2349-3933.ijam20172274.

10. Ghosh B, Sengupta S, Bhattacharjee R, Pal S, Saha SP, Ganguly G. Spectrum of peripheral neuropathy in eastern India. J Indian Med Assoc. 2006;104(4):170-163.

11. Gaillard WD, Weinstein S, Conry J, Pearl PL, Fazilat S, Fazilat S, et al. Prognosis of children with partial epilepsy: MRI and serial 18FDG-PET. Neurology. 2007;68(9):655659. Available from: https://dx.doi.org/10.1212/01.wnl. 0000255942.25101.8d.

12. Spooner CG, Berkovic SF, Mitchell LA, Wrennall JA, Harvey AS. New-onset temporal lobe epilepsy in children: 
Lesion on MRI predicts poor seizure outcome. Neurology. 2006;67(12):2147-2153. Available from: https://dx.doi.org/10. 1212/01.wnl.0000248189.93630.4f.

13. Gururaj G, Satishchandra P, Amudhan S. Epilepsy in India I: Epidemiology and public health. Ann Indian Acad Neurol. 2015;18(3):263-263. Available from: https://dx.doi.org/10. 4103/0972-2327.160093.

14. Murthy JMK, Narayanan J. New-onset acute symptomatic seizure in a neurological intensive care unit. Neurol India. 2007;55(2):136-136. Available from: https://dx.doi.org/10. 4103/0028-3886.32784.

15. Hauser WA, Annegers JF, Kurland LT. Incidence of Epilepsy and Unprovoked Seizures in Rochester, Minnesota: 1935-1984. Epilepsia. 1993;34(3):453-458. Available from: https://dx.doi. org/10.1111/j.1528-1157.1993.tb02586.x.

16. Werhahn KJ. Epilepsy in the Elderly. Dtsch Arztebl Int. 2009;106(9):135-177. Available from: https://dx.doi.org/10. 3238/arztebl.2009.0135.

17. Burn J, Dennis M, Bamford J, Sandercock P, Wade D, Warlow C. Epileptic seizures after a first stroke: the Oxfordshire community stroke project. BMJ. 1997;315(7122):15821587. Available from: https://dx.doi.org/10.1136/bmj.315. 7122.1582.

18. Cleary P, Shorvon S, Tallis R. Late-onset seizures as a predictor of subsequent stroke. Lancet. 2004;363(9416):1184 1186. Available from: https://dx.doi.org/10.1016/s01406736(04)15946-1.

19. Bronen RA. Epilepsy: the role of MR imaging. Am J Roentgenol. 1992;159(6):1165-1174. Available from: https: //dx.doi.org/10.2214/ajr.159.6.1442376.

20. Doescher JS, deGrauw TJ, Musick BS, Dunn DW, Kalnin AJ, Egelhoff JC. Magnetic Resonance Imaging and Electroencephalographic Findings in a Cohort of Normal Children With Newly Diagnosed Seizures. J Child Neurol. 2006;21(6):491495. Available from: https://emedicine.medscape.com/article/ 1155295-overviewLastaccessed.

21. Colosimo C, Celi G, Settecasi C, Tartaglione T, Rocco CD, Marano P. Magnetic resonance and computerized tomography of posterior cranial fossa tumors in childhood. Di erential diagnosis and assessment of lesion extent. La Radiologia Medica. 1995;90(4):386-95.

Copyright: (C) the author(s), 2020. It is an open-access article distributed under the terms of the Creative Commons Attribution License (CC BY 4.0), which permits authors to retain ownership of the copyright for their content, and allow anyone to download, reuse, reprint, modify, distribute and/or copy the content as long as the original authors and source are cited.

How to cite this article: Kaushik G, Manmohan M. Structural Abnormalities on MRI in Cases with Epilepsy. Asian J. Med. Radiol. Res. 2020;8(2):18-22.

DOI: dx.doi.org/10.47009/ajmrr.2020.8.2.3

Source of Support: Nil, Conflict of Interest: None declared.

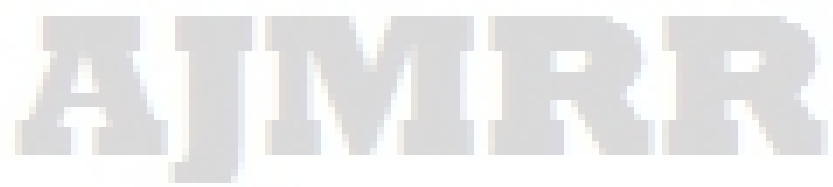

